\title{
From earth observation to human observation: Geocomputation for social science
}

\author{
LI Deren ${ }^{1,2}$, "GUO Wei ${ }^{1,2}$, CHANG Xiaomeng ${ }^{3}$, LI Xi ${ }^{1,2}$ \\ 1. State Key Laboratory of Information Engineering in Surveying, Mapping and Remote Sensing, Wuhan Uni- \\ versity, Wuhan 430079, China; \\ 2. Collaborative Innovation Center of Geospatial Technology, Wuhan 430079, China; \\ 3. Shenzhen Key Laboratory of Spatial Smart Sensing and Services, Shenzhen University, Shenzhen 518060, China
}

\begin{abstract}
It is possible to obtain vast amounts of spatiotemporal data related to human activities to support the study of human behavior and social evolution. In this context, geography, with the human-nature relationship as its core, is undergoing a transition from strictly earth observations to the observation of human activities. Geocomputation for social science is one manifestation thereof. Geocomputation for social science is an interdisciplinary approach combining remote sensing techniques, social science, and big data computation. Driven by the availability of spatially and temporally expansive big data, geocomputation for social science uses spatiotemporal statistical analyses to detect and analyze the interactions between human behavior, the natural environment, and social activities; Remote sensing (RS) observations are used as primary data. Geocomputation for social science can be used to investigate major social issues and to assess the impact of major natural and societal events, and will surely be an area of focused development in geography in the near future. We briefly review the background of geocomputation in the social sciences, discuss its definition and disciplinary characteristics, and highlight the main research foci. Several key technologies and applications are also illustrated with relevant case studies of the Syrian Civil War, typhoon transits, and traffic patterns.
\end{abstract}

Keywords: geocomputation for social science; nighttime light remote sensing; social network; traffic patterns

\section{Introduction}

Geographers are often divided according to different schools of thought, specifically, those of spatial analysis and societal theory. The former focuses on the natural phenomena on earth's surface, whereas the latter focuses on the continuous interactions between humans and their surrounding natural and built environments (Longley et al., 2005). Our global so-

Received: 2018-12-16 Accepted: 2019-04-15

Foundation: LIESMARS Special Research Funding

Author: Li Deren (1939-), Professor and Academician of Chinese Academy of Sciences, Academician of Chinese Academy of Engineering, Academician of Euro-Asia International Academy of Sciences, specialized in the research and education on spatial information science and technology represented by RS, GPS and GIS, and promoting the construction of geographic national monitoring, digital city, digital China, smart city and smart China.

E-mail:drli@whu.edu.cn

"Corresponding author: Guo Wei (1981-), PhD and Associate Professor, E-mail: guowei98032@gmail.com 
ciety however, has entered a new era, proceeding from earth observation to human observation. Similarly, modern geography has experienced decades of development, elucidating difference and diversity cross the earth's surface and the interactions between humans and the environment (McDowell, 1995). Traditional RS technology provides effective technical support for the study of natural physical phenomena that occur on the earth's surface, but it provides less support to the study of societal development. Nevertheless, the ways in which social data may be acquired and used have been greatly improved with the rapid development of mobile Internet and new observation sensors, such as nighttime light RS, and social media. Various data related to human activities can be collected, analyzed, and used, greatly enhancing the depth and breadth of related studies. Now, not only can human activities in physical space be observed, but the scope of observation also extends to the virtual environment, composed of the Internet, the Internet of things, and sensor networks. Modern geography must comply with and actively respond to this trend to better inform the sustainable development of the natural environment and human societies.

Geocomputation for social science emerged out of the need to adapt to the developments in both natural and built environments and the interactions between humans and with the environment. Earth observation technologies are transitioning to human observation, permitting the integration of social science and big data computation, providing new theories and methods for geographers to understand the deep coupling between environmental and human elements. We introduce the background of geocomputation for social science, discuss the definition and characteristics of the four disciplines included within geocomputation for social science, and review the research foci and development of the field. RS, Geographic Information Systems (GIS), and Global Navigation Satellite Systems (GNSS) are the three main vehicles for earth observation. The key technologies and value of their application in geocomputation for social science are presented using three case studies. These correspond to the geography of conflict (impact assessment of the Syrian Civil War), typhoon transits (transmission and evolution of social networks during a typhoon), and the monitoring and analysis of traffic patterns (intelligent transportation systems in Wuhan, China).

\section{Geocomputation for social science}

\subsection{Evolution of modern geography}

Since the 1950s, modern geography has evolved through three stages: (1) traditional modern geography, (2) geoinformatics, and (3) information geography (Figure 1). The human-nature relationship has always been the central theme of modern geography, but there are notable differences in the research content and methods employed during the different stages. Such differences reveal the principles of interactions between human activities, natural and built environments, and the social environment at different levels.

In the early (i.e., traditional) stage of modern geography, data on natural phenomena were acquired through surveying, observing, recording, mapping, and planning, whereas data on human activities and social phenomena were collected using questionnaires, interviews, and third-party observations. These data were then employed to understand the spatial differentiation and organization of various natural and human phenomena on the surface of the earth. However, studies on natural environmental characteristics and human activities were domi- 
nated by qualitative descriptions, and geographical research during this stage was macroscopic and empirical.

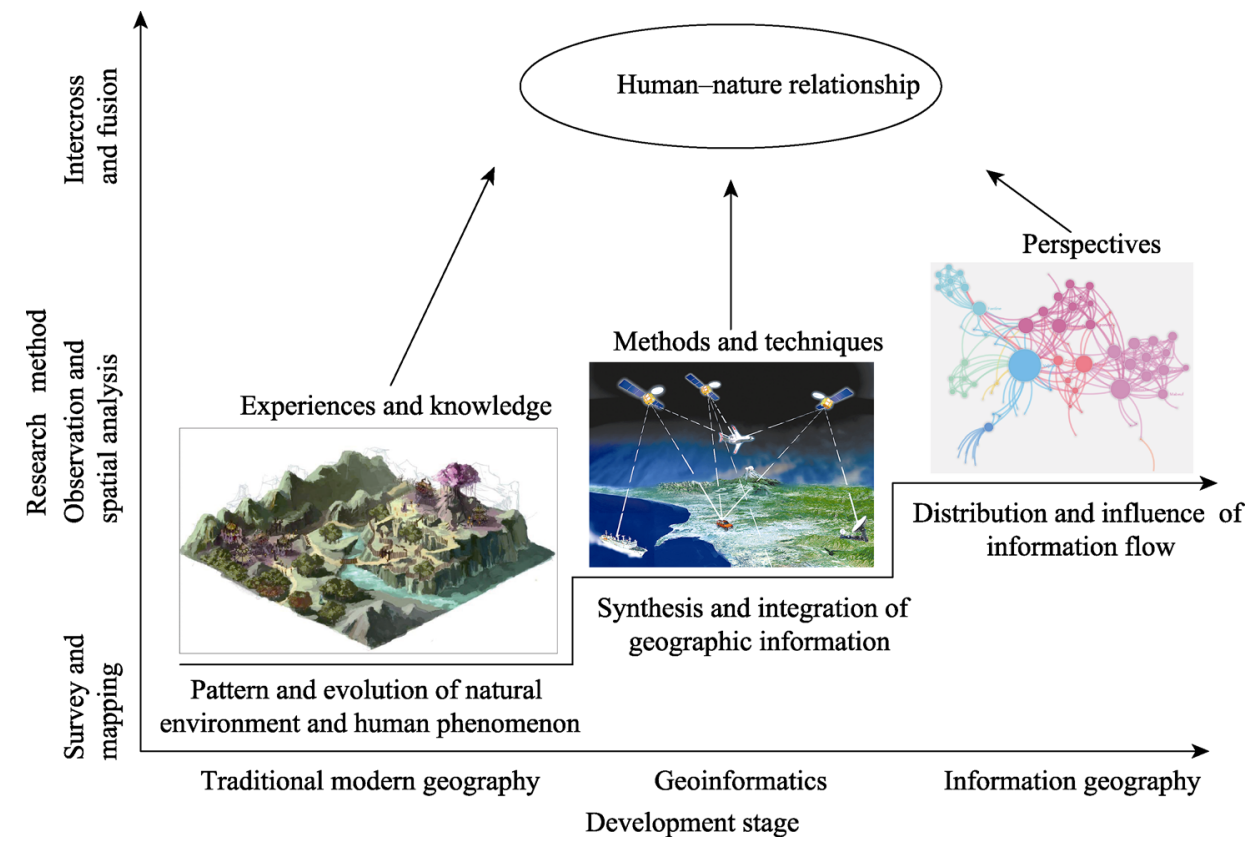

Figure 1 Development of modern geography

Economic geography, as an important branch of human geography, is defined as an interdisciplinary subject between geography and social science. It mainly studies the location and spatial organization of economic activities and their relationship with the geographical environment. Location is the place occupied by human activities (human behavior), and economic geography therefore mainly explores the general spatial law of human activities and studies the complex system of human-nature interactions. Questionnaire surveys or government statistical data are generally used to analyze and judge the combination of field research and theoretical analysis (Fan, 2011).

In the early $1960 \mathrm{~s}$, the emergence of GIS promoted the transition to geoinformatics. As a technical geographic science, geoinformatics comprises comprehensive and integrated scientific, technological, and industrial information that has proven useful for collecting, measuring, analyzing, storing, managing, displaying, disseminating, and applying data related to geographic and spatial patterns using various methods. Geoinformatics is an organic combination of surveying and mapping, photogrammetry and RS, cartography, GIS, computer graphics, satellite positioning technologies, expert system technologies, and modern communication technologies ( $\mathrm{Li}, 1996)$. Moreover, geoinformatics provides effective methods and techniques for geographic research in the information age. It emphasizes the integration and synthesis of geographic information, with $3 \mathrm{~S}$ integration technology and space-air-ground integrated earth observation networks representing typical applications.

With the development of the information age, geographic research has increasingly focused on the practical problems of people and societies. The geographic problem of human communication is the main research direction in current information geography, and it aims to study the principles underlying human activities and social evolution by analyzing spatial 
distributions and structures and the spatial influence of human information flow. Furthermore, it provides a new perspective on the indirect observation of human activities in virtual spaces, which are composed of various information flows (Yu and Shaw, 2008). Currently, sociality, intersectionality, and integration are the prominent features of this research area. Thus, modern geography has moved from traditional earth observations to human and social observations, which aim to explain the mechanisms and mutual influences of human-nature relationships at a deeper level. To achieve this goal, new theories, technologies, and systems are needed. To this end, we propose the application of geocomputation for social science. Geocomputation for social science is a new interdisciplinary approach that integrates RS techniques, social science, and big data computing methods. We hope to study the interaction between people and their environments at a deeper level by using new methods of generating RS observations to provide supporting theories and methods for solving increasingly complex social problems.

\subsection{Definition of geocomputation for social science}

Geocomputation for social science arose as a form of social computing, which was first proposed in information science (Schuler, 1994). This concept refers to social software, namely that which supports collaborative work software, such as e-mail. However, with the rise of modern information networks and the rapid development of information science and technology, new connotations and meanings are constantly being ascribed to social computing. Computational social science, as a new interdisciplinary subject within both social and information sciences, has drawn the attention of mainstream academia (Lazer et al., 2009). Computational social science aims to study social science issues, such as human social behaviors and the principles and dynamics underlying social operations, providing a new research model and paradigm for social science. Eighty percent of information related to human activities is related to geographical location and spatial distribution (Williams, 1987). Spatial features are within the domain of geography. Therefore, in order to provide better services to human societies, it is necessary to rethink and reexamine human activities and social evolution from the spatiotemporal perspective of geography and on the basis of computational social science. From this need, the concept of geocomputation for social science has arisen.

Geocomputation for social science is a new discipline that employs RS earth observations and is driven by the spatiotemporal big data that reflects surface features and human activities. It senses, analyzes, and mines categories and intensities of human activities and their influences on natural and social environments in multiple spatial and temporal dimensions. The essence of geocomputation for social science is the human-nature relationship, which is also the main focus of geography. The field of geocomputation for social science is not only limited to the physical spaces of natural and built environments, but also extends to the virtual spaces of social environments. It contains the relationship structures of large-scale crowds in physical and virtual spaces, spatiotemporal interactive activities, spatiotemporal motion trajectories, and network activities.

The methodology underlying geocomputation for social science is shown in Figure 2. Geocomputation for social science takes information flow as input generated by interactions between human activities and natural, built, and social environments. By analyzing the spa- 
tial structure and influence of information flow, the patterns of human activities and the evolution of natural and social environments can be discerned. On this basis, geocomputation for social science can be used to enhance understanding of the human-nature relationship and promote the sustainable development of societies and nature through the feedback generated by information flow.

At present, both academics and industries have developed great interest in geocomputation for social science and, in turn, produced

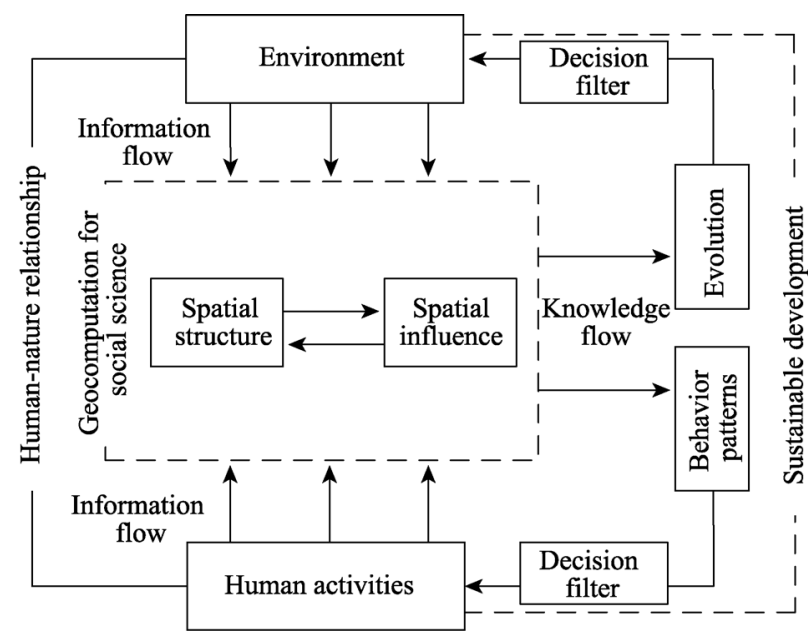

Figure 2 Schematic of the methodology of geocomputation for social science many creative studies and applications. By using deep learning, it is possible to mine vehicle information in Google Street View images and estimate the demographic structure and socioeconomic characteristics of American cities (Fei-Fei L et al., 2017). In this way, voting trends in a presidential election can be predicted, which provides a new method for the extensive transformation of traditionally labor-intensive social investigations. The spatiotemporal characteristics and influence of burglary crimes can also be revealed by correlation analyses among the characteristics of a person or community and crime distance (Xiao et al., 2018). Such work promotes the simulation and prediction of spatially correlated crime. Furthermore, several effective software tools have been developed for the spatial analysis and service of social science data, for example, the GeoDA software platform (http://geodacenter.github.io).

On June 2, 2018, the satellite Luojia-1 was successfully launched from the Jiuquan Satellite Launch Center, Inner Mongolia, China. On June 4, 2018 at 11:25:34 a.m. (UTC+8), the first nighttime light RS image was successfully transmitted. Compared with common RS, which mainly observes the changes of earth's surface and environment, nighttime light RS focuses on human-centered observations. As the first specialized nighttime light satellite in China, Luojia-1 is of groundbreaking importance to the development of nighttime light RS satellites and the application of RS in social and economic fields. Furthermore, in January 2018, Wuhan University, the University of Chicago, and the University of Michigan developed a joint research center for geocomputation for social science. The center is committed to studying the activities of human societies and uses human development as the main content. It focuses on the relationships between natural environments, social environments, and human activities and develops integrated innovations in the natural and social sciences to discern the characteristics and trends of human behavior and scientifically solve social problems.

Geocomputation for social science is a new means of understanding the principles underlying human activities and social phenomena. It will greatly promote crossover between and integration of natural and social sciences. Moreover, it provides a new direction in the development of modern geography and promotes the study of human-nature relationships at a 
deeper level.

\subsection{Characteristics of geocomputation for social science}

As the product of an interdisciplinary fusion of RS observation technology, social science, and big data computing methods, geocomputation for social science is a new discipline studying the principles and dynamics of human behaviors in space and over time. It is inherently multidimensional, with the core drive being the acquisition, input, and analysis of new spatiotemporal big data. Geocomputation for social science is characterized by four aspects: (1) new types of data, (2) the multidimensionality of space and time, (3) human activity rule mining and analysis, and (4) interdisciplinary integration.

\subsubsection{New types of data}

Currently, personal daily activities and urban development generate an overwhelming number of data. In the past, research on social topics mainly relied on questionnaire surveys or data from government statistics departments, international organizations, and media. Sociological statistical methods were then applied to describe and quantitatively analyze the data. This type of traditional data acquisition method has many deficiencies, such as high cost, low quality, poor reliability, and high processing times. It is especially difficult and less credible in countries with weak statistical monitoring or political instability. Therefore, this traditional approach has great limitations for the study of social problems.

New types of sensors, such as satellites, videos, mobile locations, and traffic trajectories, make data easier to collect and cheaper to store. It also promotes the leapfrog transformation of spatial analysis methods of modern geography from model- to data-driven. Traditional spatial analysis cannot effectively support the modeling and analysis of complex spatial processes and behaviors, because it relies heavily on the model's quantitative assumptions about the degree of abstraction and parameter settings of the real world. With the support of real-time, multi-scale, high-precision sensor data, through the association, fusion, collision, and mining of multi-source data, it provides a new perspective for complex spatial analysis, which can use spatiotemporal big data mining methods to generate value, it also produced from objectively promoted the social geography. It has driven the emergence of geocomputation for social science.

Global socioeconomic development can be monitored by nighttime light RS. Statistical analyses have shown that there is a strong correlation between the spatial distribution of global gross domestic products (GDPs) and nighttime light. Thus, nighttime light RS can provide a new way of monitoring the dynamics of global socioeconomics (Li et al., 2016). Geocomputation for social science uses the internet, internet of things, and cloud computing as new technological resources. By collecting big data and refining the information, researchers' natural intelligence and computers' artificial intelligence can be deeply integrated. Research on human activities and social development, based on the comprehensive analysis and mining of spatiotemporal big data, not only represents a change in the approach of scientific research, but also in the ways in which people think. This is the major problem in modern geography today.

\subsubsection{Multidimensionality of space and time}

Spatiotemporal characteristics are important attributes of geocomputation for social science 
that differ from traditional computational social science. By fusing spatiotemporal and big data, spatiotemporal big data contain the correlations of objects, processes, events in space, time, and semantics. These data have three basic characteristics: (1) the spatial dimension, (2) the attribute dimension, and (3) the time dimension. The spatial dimension refers to the geographic information with accurate three-dimensional spatial position (i.e., x-, y-, and z-coordinates) or spatial distribution characteristics, and it is measurable. The attribute dimension refers to special information that can been added with many attributes, and it is multidimensional. The time dimension refers to geographic information that changes over time, and it is dynamic (Elvidge et al., 1997). Compared with non-spatiotemporal data, spatiotemporal big data can reflect the spatiotemporal characteristics of human activities, such as societies, economies, cultures, occupations, and life. These data are dynamic in space, time, attribute, and dimension ( $\mathrm{Li}$ and $\mathrm{Li}, 2015)$. With the dramatic increase in big data, information and communication technologies, such as sensor networks, the internet of things, and media/social networks, have developed rapidly. The spatiotemporal big data that describe and record the complex characteristics of human societies, virtual environments, and the physical world are growing rapidly. The scale of spatiotemporal big data is increasing, and its semantics are increasingly rich.

\subsubsection{Human activity rule mining and analysis}

Rule mining and causal analysis of human activities is important in geocomputation for social science. All human activities take place in particular scenarios and are constrained by physical spaces, virtual spaces, and time (Golledge and Stimson, 1997). With direct or indirect observation of human activities in these scenarios, it is useful to discern the governing rules and understand the principles behind human behavior and social evolution. At present, RS image data, spatial media data associated with location, GNSS, and location trajectory data have been widely used to research human activities and social events. Among them, nighttime light RS can provide data on the visible light emitted from the earth's surface on cloudless nights. Moreover, much of these data are generated by human activities, such as city lights, ship lights, and burning oil wells. Urban traffic trajectory data can also be used to analyze the rules underlying human activities in physical spaces, whereas those of human activities in virtual spaces can be studied using the check-in data from social media.

\subsubsection{Interdisciplinary integration}

With the increasing popularity and accessibility of the internet, more social activities are occurring through this medium. Electronic traces, social media, digital texts, and spatial location information are the most representative social science big data. In sociology, attention is increasingly being paid to the application of information technology in social activities. Currently, geography focuses more on the observation of human activities, and the concept of geocomputation for social science was consequently generated. Geocomputation for social science is the integration of social data and theories in geography and spatial data and theories in sociology. Combining human-centered and social science theories with geospatial technologies will provide a theoretical and methodological system for studying human activities to understand and transform society and to solve complex social problems in political, economic, and cultural spheres. 


\section{Research foci of geocomputation in social science}

The generation and development of new sensors provide new perspectives and methods for the study of human activities and social phenomena and, in turn, become the main data sources of geocomputation for social science. Based on the spatiotemporal big data that are closely related to human activities, various institutions and groups around the world have performed active explorations. Current research mainly focuses on four aspects: the assessment of social and economic development, causal analysis of major social events, crowd activity in large cities, and the characteristics of human activities in virtual spaces. The research foci of geocomputation in social science are shown in Table 1.

Table 1 Research foci of geocomputation in social science

\begin{tabular}{|c|c|c|}
\hline Research topics & Data type & Main results and conclusions \\
\hline \multirow{9}{*}{$\begin{array}{l}\text { Assessment of social } \\
\text { and economic } \\
\text { development }\end{array}$} & \multirow[t]{3}{*}{ Nighttime light image } & $\begin{array}{l}\text { Investigation on the spatial patterns of economic recessions } \\
\text { (Li et al., 2014) }\end{array}$ \\
\hline & & $\begin{array}{l}\text { Identification and evolution analysis of urban agglomeration } \\
\text { and urban system (Yu et al., 2014) }\end{array}$ \\
\hline & & $\begin{array}{l}\text { Analyses of the impact of urbanization on ecological environ- } \\
\text { ment (He et al., 2015) }\end{array}$ \\
\hline & Mobile phone metadata & $\begin{array}{l}\text { Socioeconomic status and socioeconomic characteristic of } \\
\text { people were inferred (Blumenstock et al., 2015) }\end{array}$ \\
\hline & Remote sensing image & $\begin{array}{l}\text { Population consumption and asset changes were predicted } \\
\text { (Jean et al., 2016) }\end{array}$ \\
\hline & $\begin{array}{l}\text { Remote sensing image } \\
\text { and online rental infor- } \\
\text { mation }\end{array}$ & $\begin{array}{l}\text { Poverty measurement of urban internal space (Yuan et al., } \\
\text { 2018) }\end{array}$ \\
\hline & Street view image & $\begin{array}{l}\text { The demographics and socioeconomic characteristics were } \\
\text { estimated and voting trends in presidential elections were pre- } \\
\text { dicted (Fei-Fei L, 2017) }\end{array}$ \\
\hline & & $\begin{array}{l}\text { Quantifying the street-visible greenery and estimating the } \\
\text { economic benefits that the neighbor visible greenery would } \\
\text { have on residential developments (Zhang and Dong, 2018) }\end{array}$ \\
\hline & $\begin{array}{l}\text { High-speed railway and } \\
\text { airline networks }\end{array}$ & $\begin{array}{l}\text { The influence of high-speed railway and air networks on } \\
\text { urban system was analyzed (Yang et al., 2018) }\end{array}$ \\
\hline \multirow{4}{*}{$\begin{array}{l}\text { Causal analysis of } \\
\text { major social events }\end{array}$} & \multirow[t]{4}{*}{ Nighttime light image } & The impact of war was assessed (Witmer et al., 2011) \\
\hline & & Monitoring humanitarian crises (Li et al., 2011) \\
\hline & & $\begin{array}{l}\text { The correlation between night light change and disaster loss in } \\
\text { earthquake-stricken areas was analyzed (Zhang et al., 2018) }\end{array}$ \\
\hline & & $\begin{array}{l}\text { Assessing the impact of three types of natural disasters: earth- } \\
\text { quakes, floods, and storms (Zhao et al., 2018) }\end{array}$ \\
\hline \multirow{4}{*}{$\begin{array}{l}\text { Crowd activity in } \\
\text { large cities }\end{array}$} & Mobile phone data & $\begin{array}{l}\text { The taxi demand characteristics and potential land use patterns } \\
\text { between two places were revealed (Kang et al., 2013) } \\
\text { Human mobility was speculated to improve traffic planning } \\
\text { and urban planning management (Zhu et al., 2015) } \\
\text { The disparities in park access were explored (Xiao et al., 2019) }\end{array}$ \\
\hline & Nighttime light image & The house vacancy rate was estimated. (Chen et al., 2015) \\
\hline & $\begin{array}{l}\text { Nighttime light image } \\
\text { and cancer registry data }\end{array}$ & $\begin{array}{l}\text { There is a significant correlation between the intensity of light at } \\
\text { night and the incidence of breast cancer. (Bauer et al., 2013) }\end{array}$ \\
\hline & $\begin{array}{l}\text { Nighttime light image } \\
\text { and taxi trajectories data }\end{array}$ & $\begin{array}{l}\text { The nighttime light and taxi trajectory data were integrated to } \\
\text { estimate population at micro levels. (Yu et al., 2019) }\end{array}$ \\
\hline
\end{tabular}


(Continued)

\begin{tabular}{|c|c|c|}
\hline Research topics & Data type & Main results and conclusions \\
\hline \multirow{7}{*}{$\begin{array}{l}\text { Crowd activity in } \\
\text { large cities }\end{array}$} & $\begin{array}{l}\text { Taxi trajecto- } \\
\text { ries data }\end{array}$ & $\begin{array}{l}\text { The demand-supply of healthcare services was analyzed } \\
\text { (Chen et al., 2018) }\end{array}$ \\
\hline & $\begin{array}{l}\text { Sharing bikes' } \\
\text { trajectories }\end{array}$ & $\begin{array}{l}\text { Illegal parking behaviors were detected to ease traffic congestion } \\
\text { (He et al., 2018) }\end{array}$ \\
\hline & $\begin{array}{l}\text { Transit smart } \\
\text { card data }\end{array}$ & $\begin{array}{l}\text { To discuss the influence of housing burden pressure on housing spatial } \\
\text { distribution pattern (Li et al., 2018) }\end{array}$ \\
\hline & $\begin{array}{l}\text { Social media } \\
\text { data }\end{array}$ & $\begin{array}{l}\text { The development trend and spatial distribution law of emergency events } \\
\text { are mined to provide decision-making basis for disaster emergency re- } \\
\text { sponse (Wang et al., 2016) }\end{array}$ \\
\hline & $\begin{array}{l}\text { Street view } \\
\text { image }\end{array}$ & $\begin{array}{l}\text { Image detection methods are used to determine the presence of pedestrian } \\
\text { and extract pedestrian count data (Li et al., 2015) }\end{array}$ \\
\hline & & $\begin{array}{l}\text { Examining associations between exposure to green and blue spaces as } \\
\text { well as geriatric depression (Helbich et al., 2019) }\end{array}$ \\
\hline & Crime data & $\begin{array}{l}\text { It reveals the spatial-temporal characteristics and influences of crimes, } \\
\text { and predicts of space crimes (Liu et al., 2018) }\end{array}$ \\
\hline \multirow{3}{*}{$\begin{array}{l}\text { Analysis of human } \\
\text { activity in virtual } \\
\text { space }\end{array}$} & \multirow[t]{3}{*}{$\begin{array}{l}\text { Social media } \\
\text { data }\end{array}$} & $\begin{array}{l}\text { It extracts the public interest and attention to the event and predicts the } \\
\text { reported disease level (Signorini et al., 2011) }\end{array}$ \\
\hline & & $\begin{array}{l}\text { It reveals the users who made political comments onsocial networking } \\
\text { sites were mostly urban males (Barbera and Rivero., 2014) }\end{array}$ \\
\hline & & $\begin{array}{l}\text { The traveler's family and workplace were estimated and the characteris- } \\
\text { tics of human travel were depicted (Chang et al., 2017) }\end{array}$ \\
\hline
\end{tabular}

\subsection{Assessment of social and economic development}

It has been demonstrated that night lighting is strongly correlated with population density and GDP at different scales in socioeconomic parameter estimation, urbanization and regional development, and assessment of energy consumption monitoring. Nighttime light RS provides a new approach for the spatialization of social and economic indices. Defense Meteorological Satellite Program-Operational Linescan System (DMSP-OLS) data can be used for regression analysis between the area of night lighting and GDP in 21 American countries (Elvidge et al., 1997). It has been shown that night lighting is strongly correlated with GDP, with a determination coefficient of 0.97 , and its density and usage rate can reflect a region's prosperity. Furthermore, the spatialization and gridding of population data can provide important data for research on regional economies, disasters, and global environmental change. Nighttime light RS has also been used to assess human presence and activity in the Amazon region, which lacks official census statistics.

In especially poor areas, night lighting levels are usually very low and almost unchanging, which makes it difficult to study the living conditions of the poor by night lighting. To address this issue, a method of extracting socioeconomic information from high spatio-resolution satellite images for the estimation of consumer spending and asset wealth has been proposed (Jean et al., 2016). This method, combined with machine learning, is a good predictor of population consumption and asset changes in many African countries. By using mobile metadata, it is possible to infer the socioeconomic status and characteristics of people and to demonstrate that the predicted properties of millions of individuals can accurately reconstruct the wealth distribution of an entire country, which can replace large-scale censuses and household surveys to a certain extent, saving both time and money (Blumenstock et al., 2015). 


\subsection{Causal analysis of major social events}

Nighttime light RS images can not only be used to monitor energy crises and natural disasters, but also to track the occurrence of large-scale humanitarian disasters. By using DMSP-OLS data, the impact of the war between Russia and Georgia in the Caucasus region in 2008 could be assessed (Witmer and Loughlin, 2011). Light decreases during armed conflicts, and persistent fires and large-scale refugee movements can be detected in conflict zones through changes in night lighting. By using DMSP-OLS data, it has also been possible to discern the spatial patterns of the recession during Zimbabwe's economic crisis. Furthermore, the borders of Syria represent the borders of spatial and temporal patterns of night lighting, confirming through independent and objective data that a humanitarian crisis is taking place in Syria. Extending the potential of nighttime light RS in the assessments of armed conflicts, from regional to global scales, a relationship between armed conflict and changes in night lighting has been indicated. The night lighting variation index was proposed to quantify changes in night lighting within a time series by separately compounding images for 159 countries on a yearly basis. Moreover, by calculating the night lighting ratio index between different cities in Iraq, night lighting could be directly related to socioeconomic dynamics in Iraq. Nighttime light RS is therefore an effective tool for tracking humanitarian disasters ( $\mathrm{Li}$ and $\mathrm{Li}, 2014$; Li et al., 2018).

\subsection{Crowd activity in large cities}

Zheng et al. (2014) focused on urban calculations since 2014. They aimed to understand the nature of urban problems by using big data and artificial intelligence technologies to solve various problems in cities, such as traffic congestion and environmental degradation. Their method of detecting illegal parking based on shared bike trajectories can provide effective solutions for reducing traffic congestion and improving urban management capacity (Bao et al., 2017). Human activities can further be explored by using taxi travel records and individual sports data collected by mobile phones (Kang et al., 2013). The characteristics of mobile phone records and taxi travels can be quantified, and with increasing distance, the decrement rate of taxi travels is lower than that of mobile phones. The proportion of taxi travel to mobile phone records between any two locations has also been analyzed. The results not only reflect the characteristics of taxi demand between two locations, but also reveal potential land use patterns. By combining traditional survey data and mobile tracking data, daily human activities can be predicted (Diao et al., 2015). Such data provide real-time decision-making support for improving traffic and urban planning management. Bus smart card data can be used to explore whether and to what extent the demand for housing has affected the spatial distribution of housing. Indeed, commuters often move along traffic corridors (e.g., metro lines), which indicates that residency is limited by jobs and public transportation (Gao et al., 2018).

\subsection{Analysis of human activity in virtual space}

In recent years, location data based on services such as media data, which can dynamically reflect the characteristics of human activities, have been more widely used in geographical research. Such data are increasingly seen as sensors moving with people to perceive surrounding events. An emergency topic classification model was constructed for real-time mi- 
cro-blog data (Wang et al., 2016). Valuable emergency information could be effectively identified and positioned from a large number of real-time texts. Spatiotemporal analyses are used to explore the evolution and spatial distribution of emergency events to provide data for emergency response. By effectively abstracting Twitter streams, with information on users' views and responses, it is possible to measure public interest in and attention to health-related events and to accurately predict reported disease levels (Signorini et al., 2011). Home and workplace locations can also be estimated using cell phone location data (Tu et al., 2017). Human activities are marked by check-in data on micro-blogs. Cell phone locations and social media data are aggregated to infer human travel characteristics, thereby improving understanding of urban land use.

\section{Case studies of geocomputation in social science}

\subsection{RS: Assessment of the impacts of the Syrian Civil War}

At the beginning of 2011, the Syrian Civil War broke out. Many refugees were forced to flee their homes, were displaced, and lost their lives due to a lack of food and medical resources. At present, more than 400,000 people have died, and the country has been devastated. However, it is both necessary and difficult to produce a timely and accurate assessment of the impacts of the war. The conflict environment is too dangerous for journalists, and the objectivity and neutrality of their reports cannot necessarily be guaranteed. News reports do not comprehensively cover all issues. RS satellite imagery is an objective and accurate data source. To some extent, nighttime light images can be regarded as a representation of human activities and social economies. When the social and economic system of any place changes significantly due to a disaster, the nighttime light also fluctuates violently. Additionally, nighttime light has been widely used in assessing the impacts of war because of the low cost of nighttime light.

A research team at Wuhan University conducted an in-depth study on the impact of the Syrian Civil War using nighttime light images. After DMSP-OLS nighttime light images were calibrated, denoised, and automatically relatively radiometrically calibrated, a visual comparison of two periods of nighttime light images was conducted, and the changes in nighttime light in each province were statistically analyzed. The effects of the Syrian Civil War were objectively shown, and the correlation between changes in night lighting and number of refugees was analyzed ( $\mathrm{Li}$ and $\mathrm{Li}, 2014)$. As shown in Figures $3 \mathrm{a}$ and $3 \mathrm{~b}$, by comparing the nighttime light images of DMSP-OLS between the two periods, the nighttime light intensity in Syria has sharply decreased since the outbreak of the civil war, and the lights in some towns have completely disappeared. The changes in the total amount of night lighting and luminous area in different provinces were analyzed, and the total amount of night lighting in Syria decreased by $\sim 74 \%$ between March 2011 and February 2014 (Figures $3 \mathrm{c}-3 \mathrm{~d}$ ). Among the 14 provinces in Syria, the nighttime lighting in 12 has decreased by more than $60 \%$. The largest reductions in nighttime light occur in areas where fighting is most intense, whereas reductions in places controlled by the Syrian government, such as Damascus, have been relatively limited. Moreover, linear regression was used to analyze the reduction of luminous light in different provinces and the number of refugees. Notably, the number of internally displaced persons in each province showed a linear correlation with 
nighttime light loss $\left(R^{2}=0.52\right)$. The results of this analysis confirmed that refugee migration was an important factor causing decreases in nighttime light intensity. Moreover, nighttime light images reflected the different degrees of war trauma in different regions on a smaller scale.

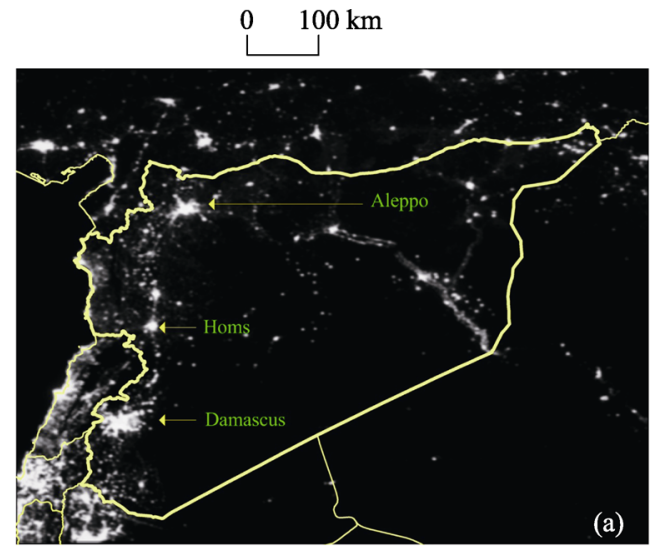

Region

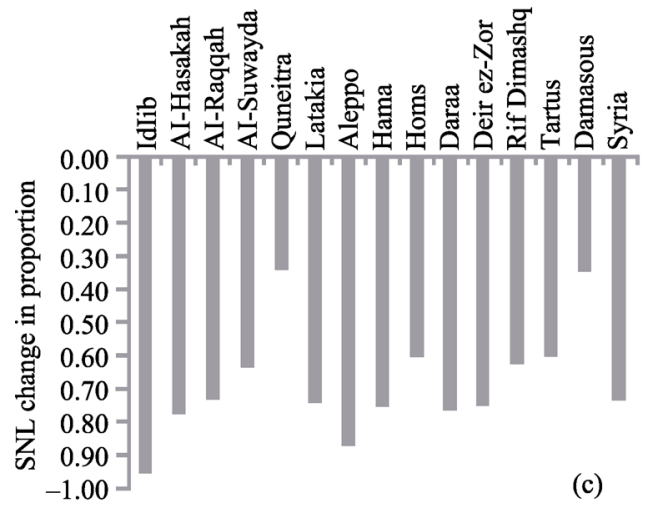

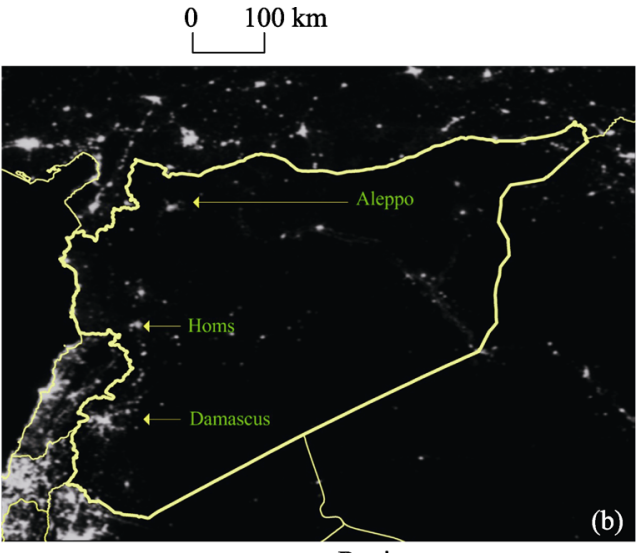

Region

(b)

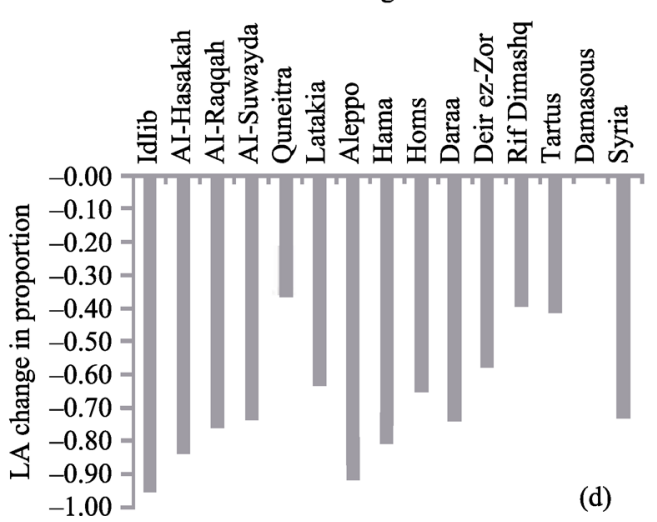

Figure 3 Monthly average nighttime light and its corresponding changes in all Syrian provinces between March 2011 and February 2014: (a) monthly average nighttime light in March 2011; (b) monthly average nighttime light in February 2014; (c) sum of nighttime light (SNL); (d) lit area (LA)

Spatial and temporal analyses of nighttime light images are important ways of evaluating the impacts of war. Figure 4 shows the results of normalization and cluster analysis of DMSP-OLS nighttime light images over 38 months since the outbreak of the Syrian Civil War. Regardless of the number of cluster categories (i.e., two or three class), the categorical boundaries were highly consistent with the Syrian border. The spatiotemporal variation in nighttime lighting is divided by the Syrian national border, which not only shows that administrative boundaries have a certain impact on socioeconomic discontinuities, but also demonstrates that the spatiotemporal pattern of the Syrian Civil War can be adequately reflected by nighttime lighting.

Nighttime light images play an important role in the assessment of the impact of the Syrian Civil War. They objectively and accurately reflect the extent of the destruction of the war in Syria and can help the global public to better understand the plight of the Syrian people. This finding has captured the attention of global officials and civil organizations on the ground in Syria and played a positive role in assisting Syrian refugees (WU, 2015). 

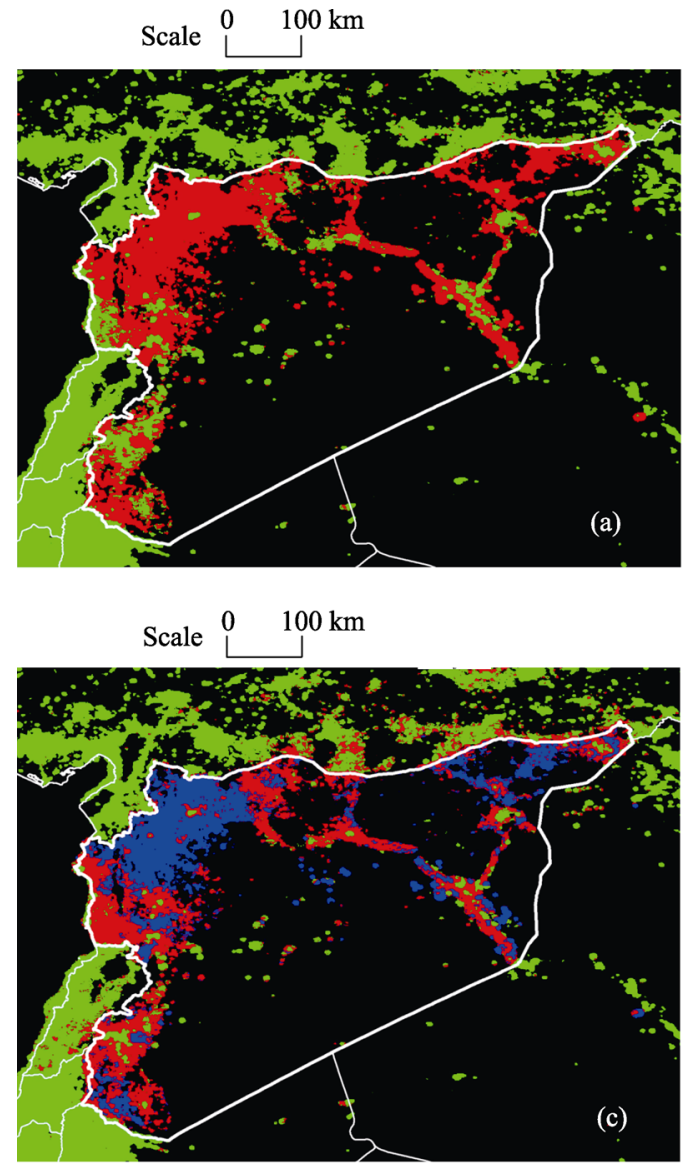
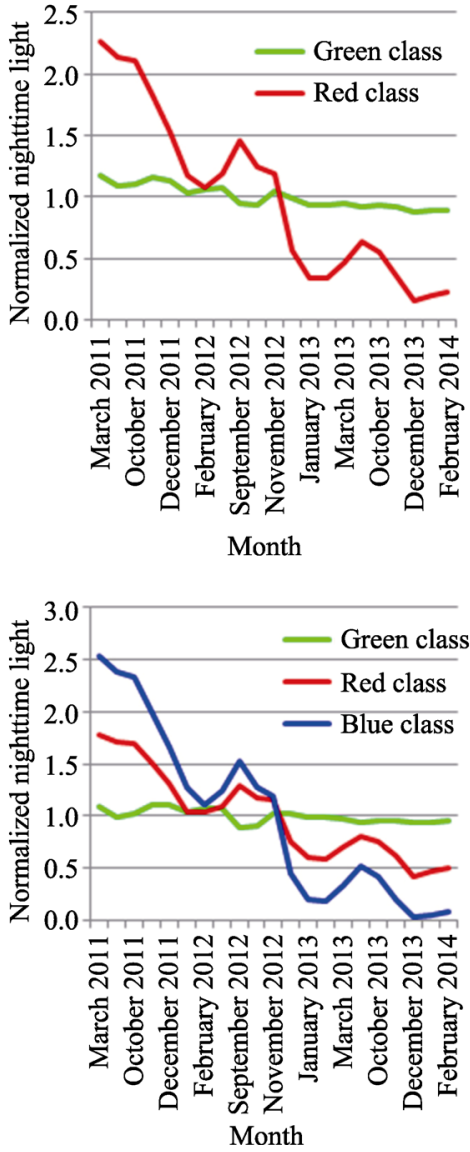

Figure 4 Class maps and centers derived from normalized time series nighttime light images: (a) two-class map; (b) class centers for the two-class map; (c) three-class map; (d) class centers for the three-class map

\subsection{GIS: Social network transmission and evolution of typhoon transits}

The propagation and evolution of social network events is the result of the joint action of events in virtual networks and real places. Events occur in a real space, spread in a virtual network space, and then spread through the wider, real-world society. Such a cycle repeats iteratively, promoting the development and extinction of events under the interaction of virtual networks and real spaces.

The spatiotemporal propagation of a super typhoon in physical space, after it became a focal topic in social network space, has been studied using micro-blog data. Figure 5 shows the key space-time nodes in the evolution of a super typhoon over space and time. The evolution consists of the following stages: tropical disturbance, tropical depression, tropical storm, severe tropical storm, first-class typhoon, second-class typhoon, fourth-class typhoon, landing in Taiwan, China, landing in Fujian, China, typhoon weakening, and typhoon demise. This is the spatiotemporal propagation path and evolution of the social network around the micro-blog topic of the typhoon. The life cycle of events in cyberspace was consistent with that of the typhoon in physical space, which lasted for approximately half a month. The discussion of events on the network every day presented a "twin peak" pattern. On the tenth 
day after typhoon formation, a peak occurred during its landfall in Fujian. From the perspective of the spatial transmission mode, two modes were presented according to the process of typhoon development. The earlier events presented a point source diffusion mode in cyberspace. These point sources were mainly meteorological enthusiasts. For this typhoon event and future potential developments, these enthusiasts exhibited exceptional expertise and foresight. The later transmission mode coincided with the structure of China's urban network, presenting a diamond-like network structure. The media, government agencies, and influential bloggers on the internet became point sources for information on the event to spread.
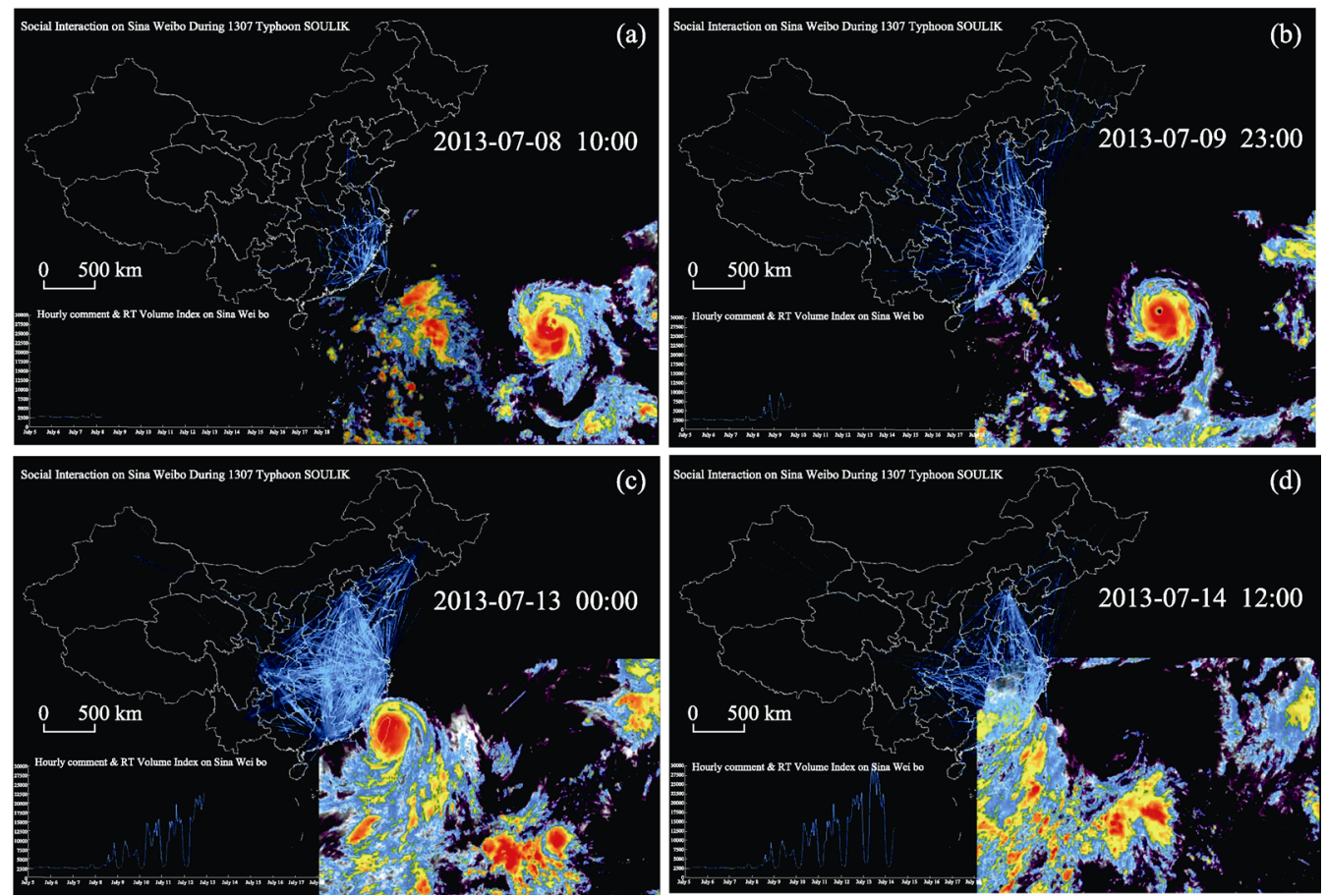

Figure 5 Spatiotemporal propagation paths and evolution of micro-blog topics: (a) tropical disturbance; (b) super typhoon; (c) landing in Fujian; (d) typhoon demise

\subsection{GNSS: Smart traffic supervision platform in Wuhan}

Traffic congestion is an important issue in the process of urban motorization and modernization. It greatly reduces the efficiency of urban operations and poses severe challenges to the sustainable development of cities. A smart traffic supervision platform in Wuhan, built by the research team of Wuhan University on the basis of "internet + big data," has been effective in solving urban traffic problems. A new mode of daily operation supervision and emergency disposal of traffic systems was constructed, and it enabled the comprehensive monitoring of people, vehicles, roads, enterprises, and the environment.

As shown in Figure 6, with spatial location as the core, the data from vehicle GPS, road induction coils, video monitoring, and other massive spatiotemporal data were integrated. The movement tracks and behavioral patterns of pedestrians and vehicles were uncovered and deduced by holographic perception, spatiotemporal analysis, and data mining. The system is capable of making real-time predictions of traffic congestion in 30 min increments as well as providing qualitative results for high-occurrence areas and roads of traffic accidents 
in $30 \mathrm{~min}$ increments to effectively guide police resources for conducting targeted guidance and disposal. In 2017, the congestion ranking of Wuhan declined from 23rd to 48th, realizing a new mode of "seven quick" for congestion accidents in which the closed loop treatment time was reduced from 7 min to $90 \mathrm{~s}$. Traffic congestion in Wuhan has consequently been greatly reduced.

\section{Q Smart traffic data brain in Wuhan - assessment of emergency dredging}

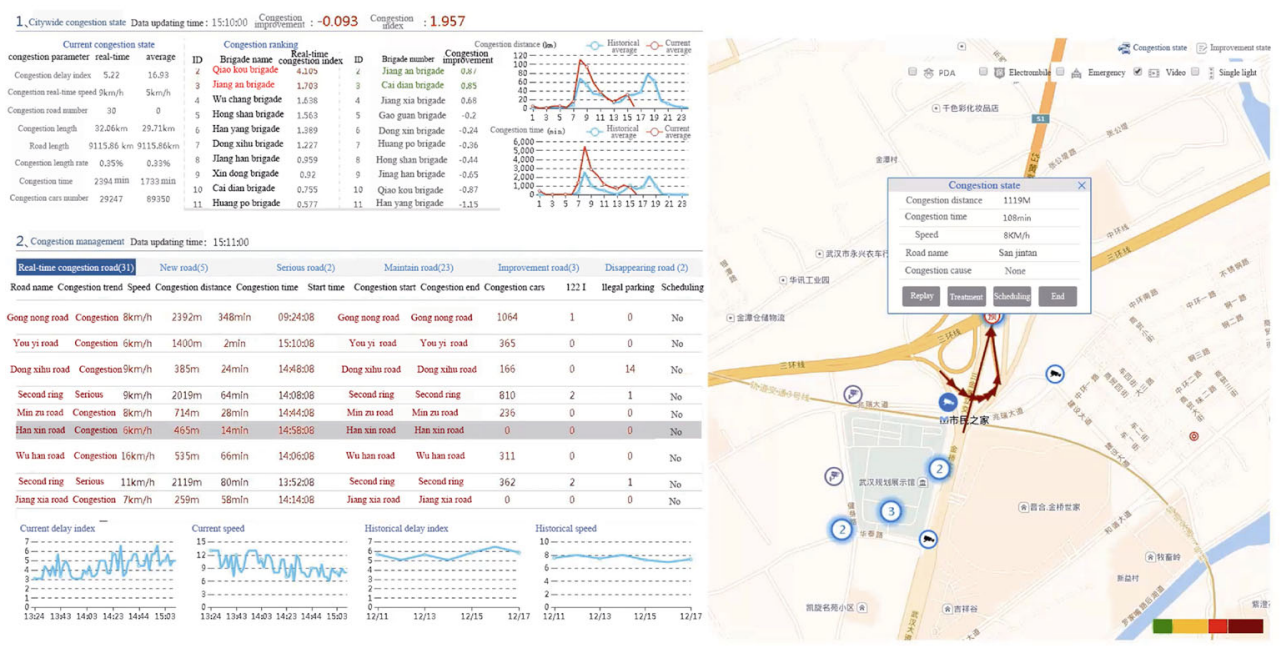

Figure 6 Smart traffic data brain in Wuhan: Assessment of emergency dredging

If water cannot be discharged in time during heavy rains, traveling is affected, which causes traffic congestion and possibly water and power outages. Many social problems caused by the untimely treatment of rainfall disasters have limited the social stability and economic development of cities to some extent. As shown in Figure 7, taxi GPS tracks may be used to simulate the mean speed of each section on the smart traffic supervision platform

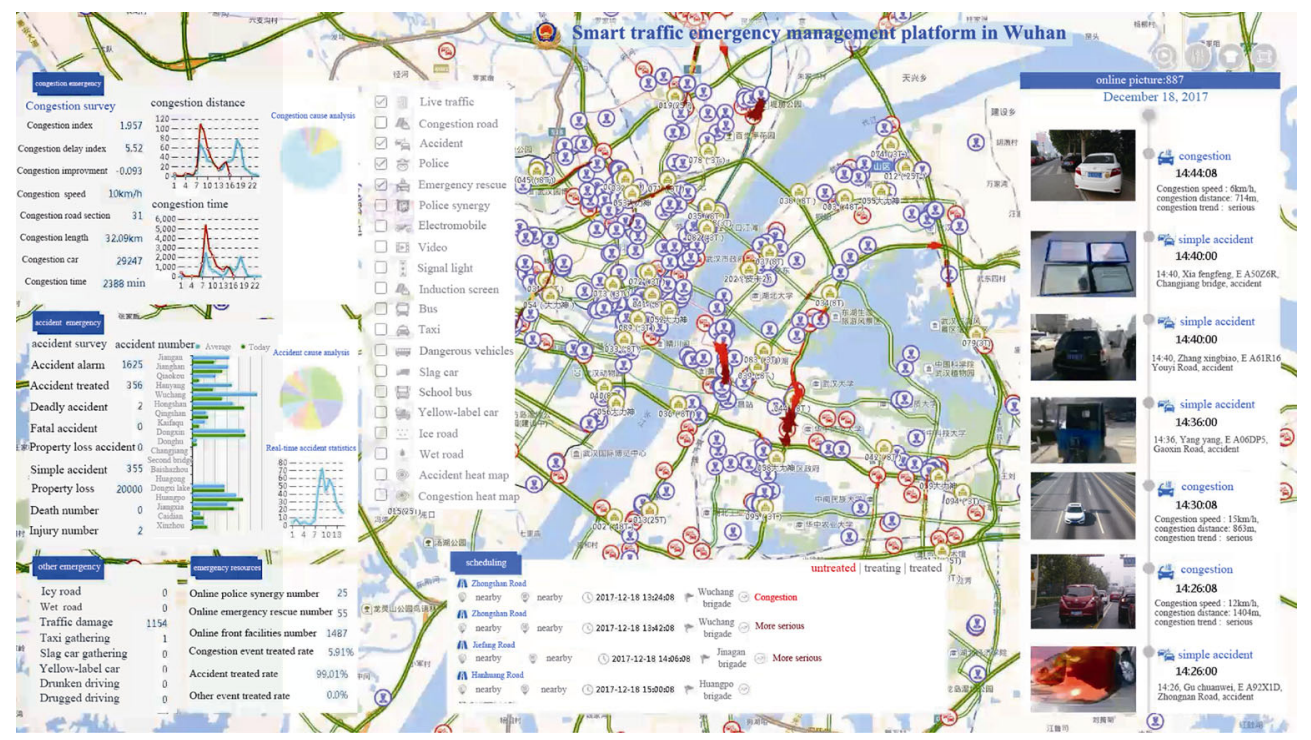

Figure 7 Smart traffic management brain in Wuhan: Smart emergency platform 
in Wuhan. By comparing these data with historical speeds to estimate potential waterlogged sections, and with the addition of manual reporting, sections can be accurately warned and promptly managed by the police. These operations can minimize the downstream effects of natural disasters on the normal operation of urban functions.

Drugged and drunk driving is prohibited for motor vehicle drivers. These activities present hidden dangers and are a frequent cause of road accidents. The Wuhan smart traffic supervision platform can access information of high-risk vehicles and use video monitoring, face recognition, vehicle recognition, and other technologies to conduct real-time monitoring of the illegal behaviors of drivers, such as drugged and drunk driving. Warnings are issued once the dangerous driver has been identified on the road. The police can immediately arrest suspects after they determine their primary activity areas, travel tracks, and vehicle locations. At present, a number of illegal activities have been successfully detected, thus improving social security (China Central Television, 2017).

\section{Conclusions}

The emergence and development of mobile internet and various other new observation sensors have profoundly changed the lifestyles of people around the world, providing new ideas for people to observe their own activities and study the evolution of society. Previous earth observations have increasingly failed to meet the demand for human observations in the real world, and society has entered an era in which progress from earth observations to human observations is needed. The massive number of spatiotemporal big data that are intimately linked to human activities is both an opportunity and a challenge to make better use of these data. In the future, more social problems may be solved by means of geocomputation for social science, in which the deeper intersection and integration of the natural and social sciences is promoted from the perspective of geography. Integrated research using geospatial informatics in the natural and social sciences will promote the sustainable development of human societies and nature.

\section{References}

Bao J, He T, Ruan S et al., 2017. Planning bike lanes based on sharing-bikes' trajectories. In: KDD '17 Proceedings of the 23rd ACM SIGKDD International Conference on Knowledge Discovery and Data Mining. New York: ACM, 1377-1386.

Barbera P, Rivero G, 2014. Understanding the political representativeness of Twitter users. Social Science Computer Review, 33(6): 712-729.

Bauer S E, Wagner S E, Burch J et al., 2013. A case-referent study: Light at night and breast cancer risk in Georgia. International Journal of Health Geographics, 12: 23. doi: 10.1186/1476-072X-12-23.

Blumenstock J, Cadamuro G, On R, 2015. Predicting poverty and wealth from mobile phone metadata. Science, 350(6264): 1073-1076.

Chen Y M, Wang B B, Liu X P et al., 2018. Mapping the spatial disparities in urban health care services using taxi trajectories data. Transactions in GIS, 22(2): 602-615.

Chen, Z Q, Yu B L, Hu Y J et al., 2015. Estimating house vacancy rate in metropolitan areas using NPP-VIIRS nighttime light composite data. IEEE Journal of Selected Topics in Applied Earth Observations and Remote Sensing, 8(5): 2188-2197.

China Central Television, 2017. More than 60 drug-related vehicles were seized and 15 people were forcibly de- 
toxified in Wuhan, Hubei province. Retrieved August 26, 2017, from http://news.cctv.com/2017/08/26/ARTIOTOcTGJBrguuAH58pC0U170826.shtml.

Diao M, Zhu Y, Ferreira Jr J et al., 2015. Inferring individual daily activities from mobile phone traces: A Boston example. Environment and Planning B-Planning \& Design, 43(5): 920-940.

Elvidge C D, Baugh K E, Kihn E A et al., 1997. Relation between satellite observed visible-near infrared emissions, population, economic activity and electric power consumption. International Journal of Remote Sensing, 18(6): 1373-1379.

Fan J, 2011. Perspective on the development process of Human-Economic Geography and regional development studies: On the evolution of the field in the Institute of Geographic Sciences and Natural Resources Research of CAS. Progress in Geography, 30(4): 387-396. (in Chinese)

Gao Q, Li Q, Yue Y et al., 2018. Exploring changes in the spatial distribution of the low-to-moderate income group using transit smart card data. Computers, Environment \& Urban Systems, 72: 68-77.

Gebru T, Krause J, Wang Y et al., 2017. Using deep learning and Google Street View to estimate the demographic makeup of neighborhoods across the United States. Proceedings of the National Academy of Sciences of the United States of America, 114(50): 13108-13113.

Golledge R G, Stimson R J, 1997. Spatial Behavior: A Geographic Perspective. New York: Guilford Press, 620 p.

He C Y, Liu Z F, Tian J et al., 2014. Urban expansion dynamics and natural habitat loss in China: A multiscale landscape perspective. Global Change Biology, 20(9): 2886-2902.

He T F, Bao J, Li R Y et al., 2018. Detecting vehicle illegal parking events using sharing bikes' trajectories. In: KDD '18 Proceedings of the 24th ACM SIGKDD International Conference on Knowledge Discovery \& Data Mining. New York: ACM, 340-349.

Helbich M, Yao Y, Liu Y et al., 2019. Using deep learning to examine street view green and blue spaces and their associations with geriatric depression in Beijing, China. Environment International, 126: 107-117.

Jean N, Burke M, Xie M et al., 2016. Combining satellite imagery and machine learning to predict poverty. Science, 353(6301): 790-794.

Kang C, Sobolevsky S, Liu Y et al., 2013. Exploring human movements in Singapore: A comparative analysis based on mobile phone and taxicab usages. In: The 19th ACM SIGKDD International Conference on Knowledge Discovery and Data Mining. Chicago, IL.

Lazer D, Pentland A, Adamic L et al., 2009. Computational social science. Science, 323(5915): 721-723.

Li D, 1996. On the formation of geomatics and its cross-century development. World Sci-Tech $R \& D, 5: 1-8$.

Li D, Li X, 2015. An overview on data mining of nighttime light remote sensing. Acta Geodaeticaet Cartographica Sinica, 44(6): 591-601. (in Chinese)

Li D, Ma J, Shao Z, 2015. The application of spatial temporal big data. Satellite Application, 9: 7-11.

Li D, Zhao X, Li X, 2016. Remote sensing of human beings: A perspective from nighttime light. Geo-spatial Information Science, 19(1): 69-79.

Li X, Li D, 2014. Can night-time light images play a role in evaluating the Syrian Crisis? International Journal of Remote Sensing, 35(18): 6648-6661.

Li X, Liu S, Jendryke M et al., 2018. Night-time light dynamics during the Iraqi Civil War. Remote Sensing, 10(6): 858. doi: https://doi.org/10.3390/rs10060858.

Longley P A, Goodchild M F, Maguire D J et al., 2005. Geographic Information Systems: Principles, Techniques, Management and Applications. 2nd ed. New York: John Wiley \& Sons, 401 p.

McDowell L, 1995. Understanding diversity: The problem of theory. In: Johnston R J, Taylor P J, Watts M J (eds.), Geographies of Global Change: Remapping the World in the Late Twentieth Century. Oxford: Blackwell, 280-294.

Schuler D, 1994. Social computing. Communications of the ACM, 37(1): 28-29.

Signorini A, Segre A M, Polgreen P M, 2011. The use of Twitter to track levels of disease activity and public concern in the U.S. during the Influenza A H1N1 pandemic. PloS One, 6(5): e19467. doi: 10.1371/journal. pone.0019467.

Tu W, Cao J, Yue Y et al., 2017. Coupling mobile phone and social media data: A new approach to understanding 
urban functions and diurnal patterns. International Journal of Geographical Information Science, 31(12): 2331-2358.

Wang Y D, Li H, Wang T et al., 2017. Modeling urban air quality trend surface using media data. Geomatics and Information Science of Wuhan University, 42(1): 14-20. (in Chinese)

Williams R E, 1987. Selling a geographical information system to government policy makers. Papers from the 1987 Annual Conference of the Urban and Regional Information Systems Association. Des Plaines, IL: Urisa.

Witmer F W, Loughlin J O, 2011. Detecting the effects of wars in the Caucasus regions of Russia and Georgia using radiometrically normalized DMSP-OLS nighttime lights imagery. GIScience \& Remote Sensing, 48(4): $478-500$.

Wuhan University (WU), 2015. Remote sensing research on the Syrian Conflict has attracted high attention from the global media. Retrieved on March 16, 2015, from http://news.whu.edu.cn/info/1002/42972.htm.

Xiao L, Liu L, Song G et al., 2018. Journey-to-crime distances of residential burglars in China disentangled: Origin and destination effects. International Journal of Geo-Information, 7(8): 325. doi: 10.3390/ijgi7080325

Xiao Y, Wang D, Fang, 2019. Exploring the disparities in park access through mobile phone data: Evidence from Shanghai, China. Landscape and Urban Planning, 181: 80-91.

Yang H R, Dobruszkes F, Wang J E et al., 2018. Comparing China's urban systems in high-speed railway and airline networks. Journal of Transport Geography, 68: 233-244.

Yin L, Cheng Q M, Wang Z X et al., 2015. 'Big data' for pedestrian volume: Exploring the use of Google Street View images for pedestrian counts. Applied Geography, 63: 337-345.

Yu B L, Lian T, Huang Y X et al., 2019. Integration of nighttime light remote sensing images and taxi GPS tracking data for population surface enhancement. International Journal of Geographical Information Science, 33(4): 687-706.

Yu B L, Shu S, Liu H X et al., 2014. Object-based spatial cluster analysis of urban landscape pattern using nighttime light satellite images: A case study of China. International Journal of Geographical Information Science, 28(11): 2328-2355.

Yu H, Shaw S-L, 2008. Exploring potential human activities in physical and virtual spaces: A spatio-temporal GIS approach. International Journal of Geographical Information Science, 22(4): 409-430.

Yuan Y, Liu J, Chen Y M et al., 2018. Poverty measurement of urban internal space based on remote sensing images and online rental information: A case study of the city core of Guangzhou. Human Geography, 33(3): 60-67. (in Chinese)

Zhang B J, 2018. Analysis of the inter-annual variation of nighttime lights in the most affected area of Wenchuan earthquake from 2003 to 2013. Journal of Catastrophology, 33(1): 12-18. (in Chinese)

Zhang Y L, Dong R C, 2018. Impacts of street-visible greenery on housing prices: Evidence from a hedonic price model and a massive street view image dataset in Beijing. International Journal of Geo-Information, 7(3): 104. doi: 10.3390/ijgi7030104.

Zhao X Z, Yu B L, Liu Y et al., 2018. NPP-VIIRS DNB daily data in natural disaster assessment: Evidence from selected case studies. Remote Sensing, 10(10): 1526. doi: 10.3390/rs10101526.

Zheng Y, Capra L, Wolfson O et al., 2014. Urban computing: Concepts, methodologies, and applications. ACM Transactions on Intelligent Systems and Technology, 5(3): 38. doi: http://dx.doi.org/10.1145/2629592. 